Article

\title{
Financial Risk Contagion in Stock Markets: Causality and Measurement Aspects
}

\author{
Guoxiang $\mathrm{Xu}^{1,2}$ and Wangfeng Gao ${ }^{1, *}$ \\ 1 School of Statistics and Management, Shanghai University of Finance and Economics, Shanghai 200433, \\ China; xugxiang@mail.shufe.edu.cn \\ 2 Research Center for Applied Statistics, Shanghai University of Finance and Economics, \\ Shanghai 200433, China \\ * Correspondence: gaowfeng@163.sufe.edu.cn
}

Received: 21 January 2019; Accepted: 27 February 2019; Published: 6 March 2019

check for updates

\begin{abstract}
As global financial markets become highly dependent on each other, risk contagion among stock markets is a primary feature of progressing globalization, which poses uncertainties for government agencies. The deficiency of previous studies is that it is difficult to accurately grasp the direction of risk diffusion in different time periods, and to depict the intensity of risk contagion constantly. Research on causality and measurement of financial risk contagion based on nonlinear causality tests and dynamic Copula methods will help governments to allocate financial resources reasonably and effectively, thus promoting the sustainable development of the social economy and financial markets. Taking the Chinese stock market as an example, this paper evaluated the risk contagion effect between the Chinese stock market and six other stock markets including developed and emerging markets from January 2006 to December 2018. From the aspect of causality, the nonlinear Granger causality test was applied to the entire time period and the phased time periods involving specific events like the subprime mortgage crisis and the Chinese stock market crash. From the aspect of measurement, the dynamic Markov state transition Copula model was used to describe the asymmetrically dependent structure of markets, from which was derived the time-varying lower tail dependence coefficients. The results have been summarized as follows. Firstly, after the outbreak of the subprime mortgage crisis, the stock markets in developed and emerging markets unilaterally affected the Chinese stock market, indicating that China was the recipient at this stage. Then, after the outbreak of the Chinese stock market crash, the Chinese stock market had a risk contagion effect on both Japanese and Russian stock markets, indicating that China became a source of financial risk contagion within a limited area at this stage. Lastly, in terms of the degree of risk contagion, the lower tail dependence coefficients of the Chinese stock market and other markets were significantly increased after the occurrence of specific risk events, while the risk contagion degree of developed markets was higher than that of emerging markets. Policymakers can recognize and apply the characteristics of risk contagion at different stages to refrain from unreasonable institutional arrangements, thus improving the sustainability of economic development.
\end{abstract}

Keywords: risk contagion; stock market; nonlinear causality test; Markov state transition; dynamic Copula; financial sustainability

\section{Introduction}

With global economic ties becoming increasingly closer, financial capital can flow rapidly among countries, which makes the segmentation of modern international stock markets less pronounced, resulting in markets that are highly dependent on each other. Economic globalization has created convenience for portfolio management in financial markets, but financial risks may spread from one 
market to another in a very short time. Since the second half of 2007, the subprime mortgage crisis in the United States has led to a $17 \%$ decline in the U.S. stock market, while the decline in global stock markets has also expanded [1-4]. In addition, other incidents include the Asian financial crises in 1997, the European debt crisis in 2009, China's stock market disaster in 2015 and so on.

Risk contagion means that foreign shocks will be transmitted to the local market, which increases the risks of the financial market and even the whole economic operation, including liquidity risk, corporate bankruptcy, trade surplus slowdown, economic downturn, rising unemployment rate, social unrest and so on, which poses challenges to the local governments [5-7]. Therefore, it is of great significance to study the real-time linkage between stock markets and to explore the existence and characteristics of risk contagion, including causality and measurement of risk contagion [8-10]. The purpose of the study is to aid governments by providing targeted policy recommendations to avoid the uncertainty and destructiveness caused by financial risk contagion, so as to promote the sustainable development of social economies and financial markets. In addition, this study can also help financial market participants formulate diversified investment strategies for different regions and assets in the world, thus reducing external shocks, better managing risks and promoting the sustainability of investment strategies.

Due to the short development time of the Chinese financial market and inadequacy of its infrastructures, China will face greater risk contagion during market opening, which leads to the urgent study of financial risk contagion. This paper takes the Chinese stock market as an example to analyze the risk contagion caused by its linkage with external markets as a supplement and contribution to the existing research. Due to the gap between the openness and maturity of the developed stock market and the emerging stock market, it is necessary to study the risk contagion of developed and emerging markets in the Chinese stock market separately. The criteria for selecting developed stock markets and emerging stock markets are as follows: first, according to World Bank data, the country's economy ranked among the top 20 in the world in 2017; secondly, developed countries should meet the criteria set by the World Bank and emerging countries should fall within the scope of BRICS countries; thirdly, the country has at least one representative stock exchange with strong regional influence. According to the above criteria, the stock indexes of the United States, the United Kingdom, and Japan were selected as representatives of developed stock markets, and the stock indexes of India, Brazil, and Russia were selected as representatives of emerging stock markets.

The overall contribution of this paper is mainly reflected by the following four aspects. First, we evaluate the risk contagion effect between the Chinese stock market and developed and emerging markets. There is a certain gap between developed and developing countries, including economic development, market opening, and communication infrastructure. We can gain more information by studying different categories of countries separately, which will help governments to make economic policies from a more macro perspective and investors to make diversified investments with less risk.

Second, we used the nonlinear Granger causality test to study the risk contagion effects between the Chinese stock market and developed and emerging markets from the perspectives of the causality of risk contagion. Since the causality at different stages varies, the causal relationship of risk contagion direction is studied by comparing the whole time and specific time periods (segmentation based on risk events). For the first time, China's stock market crash in 2015 is regarded as representative of a local risk event.

Third, the dynamic Copula model can better describe the dynamic and asymmetric dependency structure, overcome the drawbacks of the traditional model, and obtain dynamic lower tail coefficients based on static lower tail coefficients, which can effectively depict the risk of infection over a long period of time. Using time-varying tail coefficients to measure risk contagion from different categories of markets is also an innovative approach of this study compared with previous studies.

Finally, many scholars investigate the risk contagion effect, and it is often a research subject when studying the US subprime mortgage crisis. For the first time, this paper explores whether China's risk events will also spread to other countries by selecting local risk events, namely the stock 
market disaster in China in 2015, which is a supplement to the previous research and a contribution of this paper.

The empirical results of this study show that after the outbreak of the US subprime mortgage crisis in 2008, China accepted financial risks from developed and emerging markets. However, after the collapse of China's stock market in 2015, China became a source of financial risk contagion in a limited region, including Japan and Russia. Finally, after the occurrence of specific risk events, the risk contagion between stock markets is relatively high, and the relationship with China's market is generally closer in developed markets than in emerging markets. Therefore, according to the characteristics of risk contagion, governments can make preparations for risk prevention in advance, so as to improve the sustainability and stability of social and economic development.

The logical structure of this paper is shown in Figure 1. The remainder of this paper is organized as follows. Section 2 reviews previous literature on financial risk contagion, Section 3 introduces the data and illustrates the methodology, Section 4 presents the results and discussion, while Section 5 provides a conclusion.

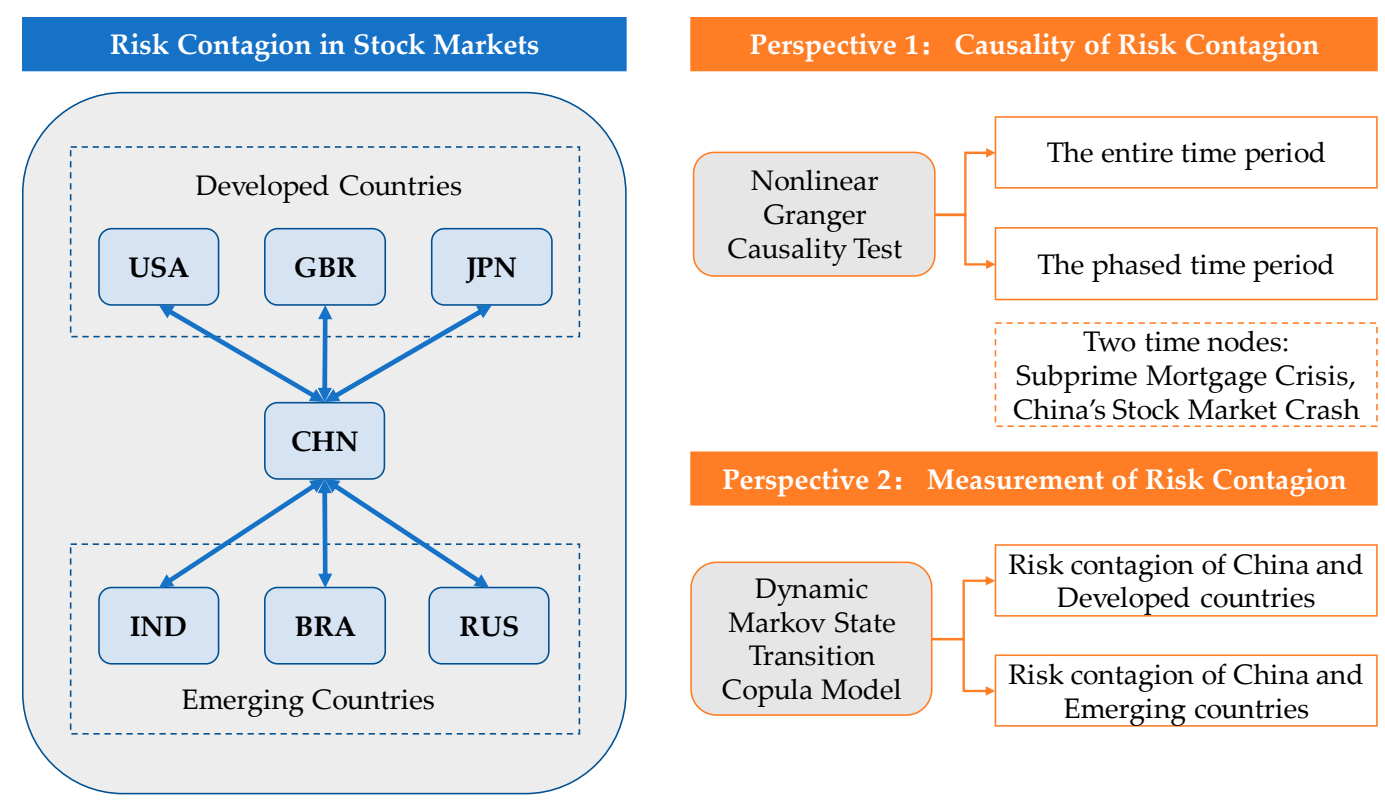

Figure 1. Framework of this paper.

\section{Literature Review}

The international contagion effect of financial risk is a very complex theoretical field considered by academia. Many scholars have carried out comprehensive, multi-angle and deep-seated research in this field. At present, the existence, causality and measurement of international financial risk contagion have been empirically tested and analyzed.

As for the existence of financial risk contagion, the early research on the existence of risk contagion was Longin and Solnik's research [11] on global financial markets during the 30 years from 1960 to 1990. It was found that the correlation of financial markets of several major developed countries in the world tended to increase, and the correlation between stock markets was higher during the period of high volatility, which confirmed the existence of risk contagion. After the financial crisis at the end of the 20th century, scholars in the field of economics paid more attention to the contagion of financial crisis, which led to more systematic research. To demonstrate its existence, scholars have introduced a large number of statistical methods to verify it on the basis of economic theory. K. Yilmaz [12] found the financial spillover effect in Asian financial markets, and the spillover effect in the "dangerous period" of financial crisis was significantly higher than that in the "non-dangerous period". At present, most scholars verify the existence of financial risk contagion effect by analyzing the dependence of financial 
asset returns in different markets. If the dependence of financial asset returns in a "dangerous period" is significantly stronger than that in a "non-dangerous period," they think that financial risk contagion is more significant. If this dependence is not observed, then risk contagion is not considered significant.

As for the causality of financial risk contagion, the most famous and common method to test the causality between two variables is the Granger causality test proposed by Granger [13], which can be used to detect the linear causality between variables. Sander and Kleimeier [14] used the Granger causality test to study the contagiousness of the Asian financial crisis, and found the change of causality at the regional and global levels. Okunev et al. [15] studied the relationship between the US real estate and S\&P 500 stock markets through the linear Granger causality test, and found a uni-directional relationship to exist from the real estate market to the stock market. However, financial time series have characteristics of non-linearity which the traditional linear Granger method cannot capture. Therefore, the research methods used in this field have gradually progressed from linear to nonlinear. Baek and Brock [16] argued that traditional linear test methods lack strong validity, so a nonlinear test method was proposed. Then, Hiemstra and Jones [17] further extended such an approach by relaxing the assumption that variables must be independent and identically distributed. Diks and Panchenko [18] proposed a new nonlinear Granger causality test method to solve this problem of excessive rejection, which is classified as a nonparametric test method. In recent years, the research based on the nonlinear methods has attracted more and more attention. Bekiros and Diks [19] studied the linear and non-linear causality between the daily spot and futures prices of West Texas Intermediate (WTI). Chen et al. [20] used the non-linear Granger causality test to study the relationship between the systemic risk of banks and insurance companies, and found that there was significant two-way causality between them. Gómez-Puig et al. [21] conducted a non-linear causal test on the yield of 10-year government bonds issued by 11 European countries, and found the intensification of the relationship between markets after the European debt crisis. De et al. [22] studied the two-way causality between public debt and GDP growth, and found that only a few countries had significant causality between them.

As for the measurement of financial risk contagion, the most classical method is based on Pearson [23] correlation coefficient, but this method can only describe linear correlation. King and Wadhwani [24] used the correlation coefficient method to study the contagiousness between the stock markets of the United States, the United Kingdom, and Japan, and found that the correlation coefficient was significantly increased after the U.S. market plunged. In recent years, risk measurement methods based on Generalized Autoregressive Conditional Heteroskedasticity (GARCH) family models have developed rapidly. The DCC-GARCH model [25] has been favored by many scholars because it has the advantage of dynamically describing the change of correlation coefficient. Chiang et al. [26] used the DCC-GARCH model to study nine Asian stock-return data series from 1990 to 2003, and found that the dynamic correlation coefficient was significantly increased during the crisis period. Syriopoulos et al. [27] also used the DCC-GARCH model to study the contagion effect of the US stock market on the BRICS stock market, and found that the contagion effect of the financial risk was most serious during the US subprime crisis in 2008. With the advancement of research, scholars have found that the dependencies between financial variables are non-linear and asymmetric. The Copula method has attracted more and more attention because of its superiority in modeling the joint distribution of variables. In theory, Sklar [28] first put forward Copula theory, since then a lot of research has been done. Joe [29] summarized the theoretical development of Copula. Nelsen [30] introduced Copula in detail. Empirically, Copula is widely used to measure the contagion effect of financial risk. Jondeau and Rockinger [31] studied the stock markets of four countries by Copula-GARCH, and found that the correlation between markets is stronger when stock returns back in the same direction. Yu et al [32] constructed a Dynamic Markov Regime Switching Copula model to measure financial market risk effects between international stock markets.

Through summarizing the previous literature, the research methods on causality and measurement of financial market risk contagion can be roughly divided into the following categories. (1) Linear correlation coefficient, is the simplest method of dependency measurement, it describes the 
linear relationship between variables, which is of little use in meeting the complexity requirements of financial data [23,24,33-35]. (2) The cointegration test based on VAR (Vector Autoregression) model, which is also linear, describing information spillovers of mean and variance among variables, but cannot measure extreme risk [36,37]. (3) GARCH (Generalized Autoregressive Conditional Heteroskedasticity) family models and multi-GARCH family models are based on the variance of error, which can describe the risk spillover between markets, including VECH-GARCH, BEKK-GARCH and DCC-GARCH models. Because the volatility spillover level is indirectly analyzed by measuring variance, this method has the problem of multicollinearity [25-27,38-40]. (4) The CoVaR (Conditional Value at Risk) model is based on conditional probability and describes conditional risk value. Risk spillover intensity can be calculated by the change rate of CoVaR relative to VaR, so as to measure the risk spillover in extreme situations. Although it is directional, it is difficult to extend the risk spillover to multiple financial markets [41-43]. (5) Fractal theory. According to whether the fractal dimension of a fractal is related to the measurement scale, the fractal structure can be divided into two categories, including unifractal (if irrelevant) and multifractal (if relevant). Multifractal theory divides complex systems into many sub-regions with different singularities, which can describe the complex statistical characteristics of price fluctuations more truly from a micro perspective. The method includes multifractal volatility method, etc. However, the method still needs to construct a dependent structure to depict the risk contagion effect after describing the volatility characteristics $[44,45]$. (6) The Granger causality test uses strict statistical analysis to test whether the past value of one market can significantly change the prediction ability of another market based on VAR model. Since the linear Granger causality test is a traditional method, the extended non-linear Granger causality test can deal well with financial data with non-linear characteristics, including the test based on regression model and non-parametric function. The test based on a regression model may result in the model being misidentified, but the non-parametric function does not have this disadvantage [13-22]. (7) The Copula function, which describes the dependency structure of variables, is the most important tool for financial correlation modeling. Compared with traditional dependency measurement, Copula can not only characterize non-linear or asymmetric dependency, but also measure tail dependency. In addition, this method can flexibly construct multivariable dependency structure, which provides convenience for generalization to multidimensional cases [28-32].

With the perfection of the theoretical research system benefiting from many previous studies, empirical analysis on financial risk contagion in the stock market has resulted in several useful findings. However, previous studies also have some shortcomings. Firstly, from the perspective of causality, many studies lack division and classification of different time periods and different markets. Secondly, from the perspective of measurement, existing literature mainly focus on static copula research, and lacks classification of different markets. Thirdly, there is a lack of consideration of risk spillovers from local risk events to other financial markets. The deficiency of previous studies is that it is difficult to accurately grasp the direction of risk diffusion in different time periods, and to continuously depict the intensity of risk contagion. If we cannot effectively find the source of risk and timely understand its impact, governments will not be able to take effective policies to maintain the stability of social economy and financial markets.

In summary, there are many methods for causality and measurement of financial risk contagion, and each method has its own advantages and disadvantages. From the perspective of technical methods, according to the principle of few defects, high flexibility and strong operability, we choose the theoretical methods suitable for this study by comparing the advantages and disadvantages of different methods. This paper explores the causality of risk contagion based on the nonlinear Granger causality test using non-parametric statistics. In addition, the dynamic Markov state transition Copula model with GARCH family model as edge distribution and SJC (Symmetrized Joe-Clayton) function as joint distribution is used to measure the risk contagion. In addition, from the perspective of empirical research, this paper carries out supplementary and innovative research on the basis of previous studies. Firstly, this paper divides the stock markets of many countries into developed markets and emerging 
markets, and studies the risk contagion effect between them and the Chinese market. Secondly, on the basis of the subprime mortgage crisis in the United States, we have included the Chinese stock market disaster in the scope of risk events in 2015, which has not been studied before. Finally, we divide the research period into three aspects: before and during the subprime mortgage crisis, before and during the stock market disaster in China in 2015, and the risk contagion performance in the whole period of time. Based on the above improvements, this paper hopes to obtain more detailed and accurate conclusions than before, so as to contribute to the previous research results.

\section{Data and Methodology}

\subsection{Data}

Since the United States, the United Kingdom, and Japan remain dominant in global economic development, we used the US S\&P 500, the UK FTSE 100, and the Japan Nikkei 225 as representatives of developed stock markets. For emerging markets, we considered the indexes of three "BRIC" countries (i.e., all BRIC countries except China): SENSEX30 in Mumbai, India; IBOVESPA in Sao Paulo, Brazil; and RTS in Russia.

This analysis used the weekly closing price data of seven nationally important indexes: the Shanghai Composite Index, S\&P 500, FTSE 100, Nikkei 225, Mumbai SENSEX30, São Paulo IBOVESPA, and Russia RTS. The time period examined is between January 1, 2006, and December 28, 2018 , for a total of $662 * 7$ data; individual vacancies in the data set were replaced by the average of the values before and after the missing data. This period of time includes the subprime mortgage crisis in the US and the stock market crash in China in 2015. These two events are important to include in studies on the risk contagion effect.

\subsection{The Concept and Production Mechanism of Risk Contagion Effect}

The risk contagion effect considered in this paper refers to the following phenomenon: when macro and micro policies remain unchanged, violent fluctuation in one financial market's price series causes other financial markets to fluctuate almost synchronously [46]. If considering "rational" factors, such as macroscopic and microscopic factors, the causes of risk contagion can be attributed to the volatility spillover and mutual dependence between different markets caused by the actual influence of infectious factors and an infectious source in the overall macro and micro market [47]. However, risk contagion is often caused by the "irrational" behaviors of market participants under specific circumstances [48], including risk aversion, lack of confidence, panic, herding, etc. The "rational" factors and the "irrational" factors influence each other and, together, result in the risk of price fluctuations in financial markets, thus providing a theoretical basis for us to better study the effects of risk contagion.

\subsection{Nonlinear Causality Test}

\subsubsection{Traditional Linear Granger Causality Test Method}

The traditional linear Granger causality test method [13] is expressed as follows: suppose that the conditional distribution of $Y_{t}$ which is determined by $Y_{t}$ and the lagging value of $X_{t}$, is the same as the conditional distribution determined by the lagging value of $Y_{t}$, expressed as a mathematical equation:

$$
f\left(y_{t} \mid y_{t-1}, \cdots, x_{t-1}, \cdots\right)=f\left(y_{t} \mid y_{t-1}, \cdots\right),
$$

then there is no Granger causality between $X_{t}$ and $Y_{t}$. Putting in another way, if using the lagging value of $X_{t}$ doesn't show significant improvement in predicting $Y_{t}$, then there is no Granger causality between $X_{t}$ and $Y_{t}$. The specific equation is as follows:

$$
Y_{t}=\sum_{i=1}^{k} \alpha_{i} Y_{t-i}+\sum_{i=1}^{k} \beta_{i} X_{t-i}+u_{1 t} .
$$


Making the null hypothesis " $H_{0}: \beta_{1}=\beta_{2}=\cdots=\beta_{k}=0$ ", we can give the corresponding alternative hypothesis as " $H_{1}$ : at least one $\beta_{i} \neq 0$ ". In order to describe the information in the equation better, we further constructed $F$ test statistics focusing on the test above:

$$
F=\frac{\left(S S E_{r}-S S E_{u}\right) / k}{S S E_{u} /(T-k N)}
$$

where $S S E_{r}$ is the sum of squared residuals under the original hypothesis. $S S E_{u}$ is the sum of squared residuals under the condition that the original hypothesis is not established, $T$ is sample size, $k$ is the maximum lag period, and $N$ represents the number of current variables in the Vector Auto Regression (VAR) model.

\subsubsection{Nonlinear Granger Causality Test Method}

We use the nonparametric test method proposed by Diks and Panchenko as the method of nonlinear Granger causality test [16-18].

Denote two strictly stable and weakly correlated time series by $\left\{X_{t}\right\}$ and $\left\{Y_{t}\right\}$ :

$$
X_{t}^{m}=\left\{X_{t}, X_{t+1}, \cdots, X_{t+m-1}\right\}, Y_{t}^{m}=\left\{Y_{t}, Y_{t+1}, \cdots, Y_{t+m-1}\right\}, m=1,2, \cdots, t=1,2, \cdots,
$$

then given $L x(\geq 1)$ and $L y(\geq 1), e>0$, then:

$$
\begin{aligned}
& X_{t-L x}^{L x}=\left(X_{t-L x}, X_{t-L x+1}, \cdots, X_{t-1}\right), L x=1,2, \cdots, t=L x+1, L x+2, \cdots, \\
& Y_{t-L y}^{L y}=\left(X_{t-L y}, X_{t-L y+1}, \cdots, X_{t-1}\right), L y=1,2, \cdots, t=L y+1, L y+2, \cdots \\
& \quad \operatorname{Pr}\left(\left\|X_{t}^{m}-X_{s}^{m}\right\|<e \mid\left\|X_{t-L x}^{L x}-X_{S-L x}^{L x}\right\|<e,\left\|Y_{t-L y}^{L y}-Y_{S-L y}^{L y}\right\|<e\right) . \\
& \quad=\operatorname{Pr}\left(\left\|X_{t}^{m}-X_{s}^{m}\right\|<e \mid\left\|X_{t-L x}^{L x}-X_{S-L x}^{L x}\right\|<e\right)
\end{aligned}
$$

If formula (7) holds, then $\left\{Y_{t}\right\}$ is not the Granger causality of $\left\{X_{t}\right\}$, where $\operatorname{Pr}(\cdot \mid \cdot)$ indicates probability, $\|\cdot\|$ indicates the largest mode. If we use the joint probability to replace the conditional probability, then the formula (7) can be shown as:

$$
\frac{C 1(m+L x, L y, e)}{C 2(L x, L y, e)}=\frac{C 3(m+L x, e)}{C 4(L x, e)},
$$

where,

$$
\begin{aligned}
& C 1(m+L x, L y, e)=\operatorname{Pr}\left(\left\|X_{t-L x}^{m+L x}-X_{s-L x}^{m+L x}\right\|<e,\left\|Y_{t-L y}^{L y}-Y_{s-L y}^{L y}\right\|<e\right) \\
& C 2(L x, L y, e)=\operatorname{Pr}\left(\left\|X_{t-L x}^{L x}-X_{s-L x}^{L x}\right\|<e,\left\|Y_{t-L y}^{L y}-Y_{s-L y}^{L y}\right\|<e\right) \\
& C 3(m+L x, e)=\operatorname{Pr}\left(\left\|X_{t-L x}^{m+L x}-X_{s-L x}^{m+L x}\right\|<e\right) \\
& C 4(L x, e)=\operatorname{Pr}\left(\left\|X_{t-L x}^{L x}-X_{s-L x}^{L x}\right\|<e\right)
\end{aligned}
$$

Let $m=L x=L y=1$, then the formula (8) can be re-described as (10):

$$
\frac{f_{X, Y, Z}(x, y, x)}{f_{Y}(y)}=\frac{f_{X, Y}(x, y)}{f_{Y}(y)} \frac{f_{Y, Z}(y, z)}{f_{Y}(y)} .
$$

To overcome the deficiencies of over-rejection, we rephrase the null hypothesis as (11):

$$
q=E\left[\left(\frac{f_{X, Y, Z}(x, y, z)}{f_{Y}(y)}-\frac{f_{X, Y}(x, y)}{f_{Y}(y)} \frac{f_{Y, Z}(y, z)}{f_{Y}(y)}\right) g(x, y, z)\right]=0,
$$

Let $g(x, y, z)=f_{Y}^{2}(y)$, then:

$$
q=E\left[f_{X, Y, Z}(x, y, z) f_{Y}(y)-f_{X, Y}(x, y) f_{Y, Z}(y, z)\right] .
$$


Denote the estimate of the local density function of the $d w$ dimensions random variable $W$ in $W_{i}$ by $f_{w}\left(W_{i}\right)$, then:

$$
f_{W}\left(W_{i}\right)=\frac{(2 \varepsilon)^{-d w}}{n-1} \sum_{j, j \neq i} I_{i j}^{W},
$$

where $I_{i j}^{W}=I\left(\left\|W_{i}-W_{j}\right\|<\varepsilon\right), \varepsilon$ is the bandwidth parameter, equals $\max \left\{C n^{-\beta}, 1.5\right\}$, where $C>0$, $\beta \in(1 / 4,1 / 3)$.

After figuring out the value of $f_{W}\left(W_{i}\right)$, we can construct the statistics $T_{n}$ as follows:

$$
T_{n}(\varepsilon)=\frac{n-1}{n(n-2)} \sum_{i}\left(f_{X, Y, Z}\left(x_{i}, y_{i}, z_{i}\right) f_{Y}\left(y_{i}\right)-f_{X, Y}\left(x_{i}, y_{i}\right) f_{Y, Z}\left(y_{i}, z_{i}\right)\right) .
$$

So, for $\varepsilon=\max \left\{C n^{-\beta}, 1.5\right\}$, and $C>0, \beta \in(1 / 4,1 / 3)$, then $T_{n}$ is normally distributed:

$$
\sqrt{n} \frac{\left(T_{n}(\varepsilon)-q\right)}{S_{n}} \stackrel{d}{\rightarrow} N(0,1),
$$

Benefiting from the nonparametric statistic $T_{n}$, we can test nonlinear causality among variables.

\subsection{Dynamic Markov State Transition Copula Model}

\subsubsection{Establishment of The Dynamic Copula Model}

According to Sklar's theorem [28], we can divide the joint distribution function into a marginal distribution and a dependent structure represented by a copula function.

Assume that two random variables $r_{1, t}$ and $r_{2, t}$ represent the rate of return of two different assets at time $t ; F_{1}\left(z_{1, t} \mid \psi_{t-1}\right)$ and $F_{2}\left(z_{2, t} \mid \psi_{t-1}\right)$ represent the conditional marginal cumulative distribution of $z_{1, t}$ and $z_{2, t} ; C_{t}$ represents the dependent structure connected by copula function; $\psi_{t-1}$ represents the information set at time $t-1$. Given the state $s_{t}$, which followed the two-state Markov chain with transition probability matrix:

$$
P=\left(\begin{array}{cc}
p_{00} & 1-p_{00} \\
1-p_{11} & p_{11}
\end{array}\right)
$$

Then the binary conditional copula function of $z_{1, t}$ and $z_{2, t}$ can be expressed as:

$$
\phi_{t}\left(z_{1, t}, z_{2, t} \mid \psi_{t-1}, s_{t}\right)=C_{t}\left(u_{t}, v_{t} \mid \psi_{t-1}, s_{t}\right)=C_{t}\left(F_{1}\left(z_{1, t} \mid \psi_{t-1}, s_{t}\right), F_{2}\left(z_{2, t} \mid \psi_{t-1}, s_{t}\right) \mid \psi_{t-1}, s_{t}\right),
$$

where $u_{t}=F_{1}\left(z_{1, t} \mid \psi_{t-1}, s_{t}\right)$ and $v_{t}=F_{2}\left(z_{2, t} \mid \psi_{t-1}, s_{t}\right)$ follow uniform distribution $U(0,1)$.

Assuming all conditional cumulative distribution functions (CDF) are differentiable, then the binary CDF of $z_{1, t}$ and $z_{2, t}$ can be given by:

$$
\varphi_{t}\left(z_{1, t}, z_{2, t} \mid \psi_{t-1}, s_{t}\right)=c_{t}\left(F_{1}\left(z_{1, t} \mid \psi_{t-1}, s_{t}\right), F_{2}\left(z_{2, t} \mid \psi_{t-1}\right) \mid \psi_{t-1}, s_{t}\right) \times f_{1}\left(z_{1, t} \mid \psi_{t-1}, s_{t}\right) \times f_{2}\left(z_{2, t} \mid \psi_{t-1}, s_{t}\right),
$$

where $c_{t}\left(u_{t}, v_{t} \mid \psi_{t-1}, s_{t}\right)=\frac{\partial^{2} C_{t}\left(u_{t}, v_{t} \mid \psi_{t-1}, s_{t}\right)}{\partial u_{t} \partial v_{t}}$ is the conditional Copula density function, $f_{1}\left(z_{1, t} \mid \psi_{t-1}, s_{t}\right)$ and $f_{2}\left(z_{2, t} \mid \psi_{t-1}, s_{t}\right)$ is the conditional density function (CDF) of $z_{1, t}$ and $z_{2, t}$.

Considering that the threshold generalized autoregressive conditional heteroskedasticity model TGARCH [49] can better reflect the asymmetry of stock market returns, and for most standardized yield sequences, AR (1)-TGARCH $(1,1)$ performs better than AR (1)-TGARCH $(1,2)$ and AR (1)-TGARCH $(2,1)$. Therefore, we used AR (p)-TGARCH $(p, q)$ as the distribution of the marginal dynamic Markov structure transition Copula function model:

$$
\begin{gathered}
r_{t}=\mu+\rho r_{t-1}+\varepsilon_{t}, \\
h_{t}=c+\varphi \varepsilon_{t-1}^{2}+\delta h_{t-1}+\gamma I\left(\varepsilon_{t}<0\right) \varepsilon_{t}^{2},
\end{gathered}
$$




$$
\varepsilon_{t}=z_{t} \sqrt{h_{t}}, z_{t} \sim \text { skewed }-t(v, \eta)
$$

where, $\varepsilon_{t}$ is the residual; $h_{t}$ is the conditional variance; $z_{t}$ obeys the skewed Student $t$ distribution proposed by Hansen [50], where $v$ is the kurtosis parameter and $\eta$ is the skewness parameter.

\subsubsection{Measurement of Financial Risk Contagion}

By its definition, financial risk contagion emphasizes the linkage effect between multiple stock markets caused by systemic risk, so the tail correlation between stock markets is used to measure financial risk contagion, which can examine whether a sharp rise or fall in one stock market will cause a sharp rise or fall in another stock market. The tail correlation coefficient can be defined in the limit form of conditional probability [41]:

$$
\begin{gathered}
\tau^{U}=\lim _{\varepsilon \rightarrow 1} P(U>\varepsilon \mid V>\varepsilon)=\lim _{\varepsilon \rightarrow 1} \frac{1-2 \varepsilon+C(\varepsilon, \varepsilon)}{1-\varepsilon}, \\
\tau^{L}=\lim _{\varepsilon \rightarrow 0} P(U<\varepsilon \mid V<\varepsilon)=\lim _{\varepsilon \rightarrow 0} \frac{C(\varepsilon, \varepsilon)}{\varepsilon}
\end{gathered}
$$

When the specific form of the Copula function between variables is determined, we can calculate the upper and lower tail correlation coefficients according to formula (22) and (23), which reflect the probability that the systemic risk of one stock market will spread to another stock market.

Considering that the joint distribution function of two variables is completely described by the Copula function connecting them, the selection of the Copula function type is particularly important. Copula functions [50,51] commonly used in research are Normal Copula, Student-t copula, Clayton copula, Gumbel copula, etc. Among them, Normal Copula and Student-t copula cannot describe the asymmetric correlat-ion between variables, and Clayton Copula can only describe the lower tail correlation, while Gumbel copula can only describe the upper tail correlation. In this paper, we used Symmetrized Joe-Clayton (SJC) copula proposed by Patton [52-54] to describe the interdependence between two markets, while SJC copula can accurately describe the asymmetric upper and lower tail relations among different variables. The expression of the distribution function of SJC copula is:

$$
C_{t}^{S J C}\left(u_{t}, v_{t} \mid \tau_{t}^{U}, \tau_{t}^{L}\right)=0.5 \cdot\left(C_{t}^{J C}\left(u_{t}, v_{t} \mid \tau_{t}^{U}, \tau_{t}^{L}\right)+C_{t}^{J C}\left(1-u_{t}, 1-v_{t} \mid \tau_{t}^{U}, \tau_{t}^{L}\right)+u_{t}+v_{t}-1\right),
$$

where $C_{t}^{J C}$ is the Joe-Clayton copula, given by:

$$
C_{t}^{J C}\left(u_{t}, v_{t} \mid \tau_{t}^{U}, \tau_{t}^{L}\right)=1-\left(1\left\{\left[1-\left(1-u_{t}\right)^{\kappa_{t}}\right]\right\}^{-\gamma_{t}}+\left[1-\left(1-v_{t}\right)^{\kappa_{t}}\right]^{-1 / \gamma_{t}}\right)^{-1 / \kappa_{t}}
$$

with, $\kappa_{t}=1 / \log _{2}\left(2-\tau_{t}^{U}\right), \gamma_{t}=-1 / \log _{2}\left(\tau_{t}^{L}\right)$, and $\tau_{t}^{U}, \tau_{t}^{L} \in(0,1)$. Two parameters $\tau_{t}^{U}$ and $\tau_{t}^{L}$ measured the upper and lower tail dependences, respectively.

The correlation of the current time can be explained by the previous correlation and the historical average of the cumulative probability of two variables. That is to say, a model similar to ARMA $(1,10)$ is used to describe the upper and lower tail correlation coefficients of SJC Copula:

$$
\tau_{t}^{K}=\Lambda\left(\overline{\alpha_{K}}+\overline{\beta_{K}} \tau_{t-1}^{K}+\overline{\alpha_{K}} \frac{1}{10} \sum_{j=1}^{10}\left|u_{t-j}-v_{t-j}\right|\right), \text { for } K=U, L
$$

where $\Lambda(x)=1 /(1+\exp (-x))$ is the logistic transformation, which can linearize the original function.

\section{Empirical Research}

Based on the preprocessed data described in Section 3, this study used the nonlinear Granger causality test and dynamic Markov state transition Copula function to conduct empirical analyses from the causality and the measurement aspects. The analysis described in this paper was performed 
with MATLAB R2014a and C Language for programming. For the test platform environment, we used the Intel Core i5-6200U with 8 GB memory and the Windows 10 Professional Edition system.

\subsection{Descriptive Statistics}

In order to describe the dynamic changes between the Chinese stock market and other countries' stock markets visually, Figure 2 shows time series charts plotted using the raw data of each country's stock market indices.

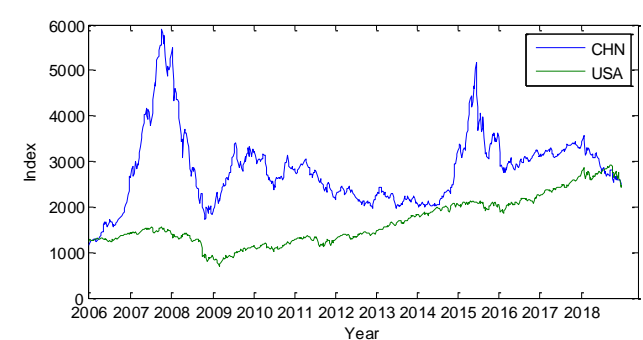

(a)

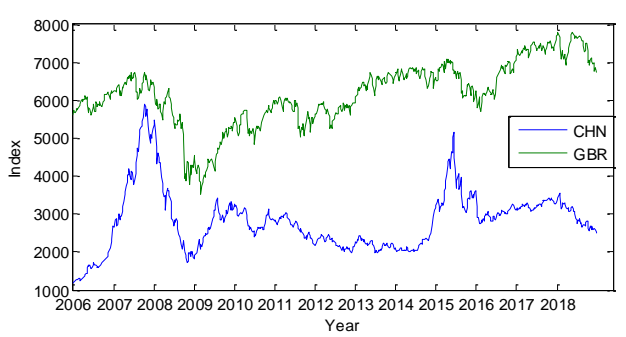

(b)

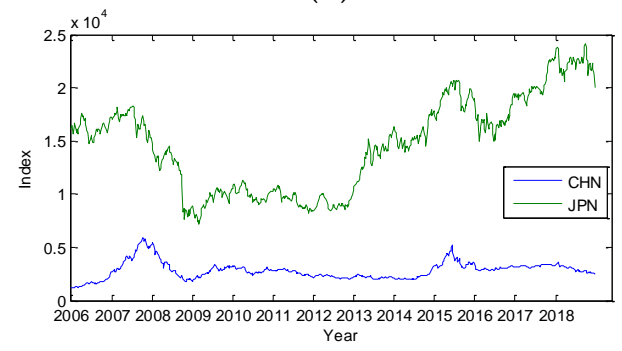

(c)

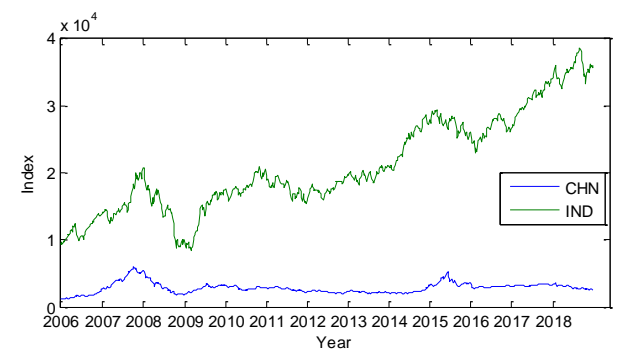

(d)

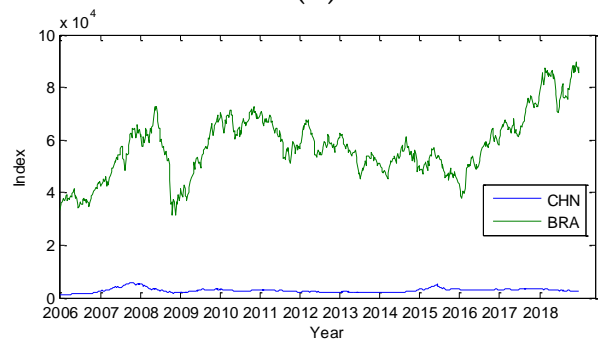

(e)

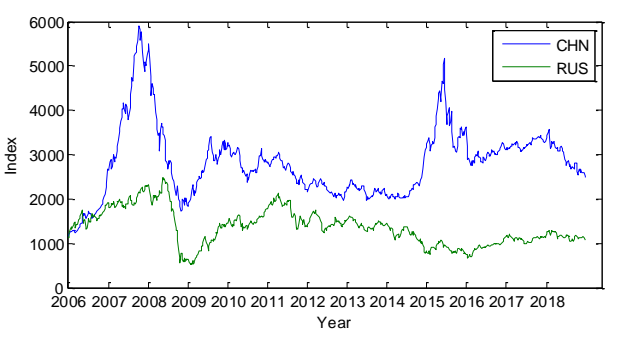

(f)

Figure 2. Stock market index series of six pairs: (a) CHN and USA; (b) CHN and GBR; (c) CHN and JPN; (d) CHN and IND; (e) CHN and BRA; (f) CHN and RUS.

For convenience, we used each country's abbreviation to represent its stock market indices: USA for the US S\&P 500; GBR for the UK FTSE 100; JPN for the Japan Nikkei 225; IND for SENSEX30 in Mumbai, India; BRA for IBOVESPA in Sao Paulo, Brazil; RUS for RTS in Russia; and CHN for Shanghai Composite Index, China.

Since preprocessing the logarithmic yield from the stock data of financial markets is an effective way to eliminate nonstationary data [55], we use the following logarithmic yield to represent the return of the stock market:

$$
r_{t, i}=100 \times\left[\ln \left(P_{t, i}\right)-\ln \left(P_{t-1, i}\right)\right],
$$

where $r_{t, i}$ means the logarithmic yield of stock markets at time $t, P_{t, i}$ and $P_{t-1, i}$ respectively represent the index of the stock market at time $t$ and time $t-1$. We use LCHN, LUSA, LGBR, LJPN, LIND, LBRA, and LRUS to represent the logarithmic yields of the seven major market indices.

In order to analyze the data better, in addition to the mean, median, maximum, minimum, standard deviation, skewness and kurtosis of the index yield, we also use the Jarque-Bera test, which 
is a goodness-of-fit test of whether sample data have the skewness and kurtosis matching a normal distribution, to conduct the normality test. The statistical results are shown in Table 1.

Table 1. Description Statistics Table.

\begin{tabular}{cccccccc}
\hline Statistics & LCHN & LUSA & LGBR & LJPN & LIND & LBRA & LRUS \\
\hline Mean & 0.1095 & 0.1000 & 0.0210 & 0.0299 & 0.1985 & 0.1330 & -0.0096 \\
Median & 0.2852 & 0.2308 & 0.2000 & 0.2339 & 0.3856 & 0.3505 & 0.1377 \\
Maximum & 13.9447 & 11.3559 & 12.5845 & 11.4496 & 13.1709 & 16.8434 & 34.1876 \\
Minimum & -14.8979 & -29.9332 & -25.7814 & -36.2552 & -21.8755 & -35.4948 & -41.9839 \\
S.D. & 3.5770 & 2.5824 & 2.5532 & 3.2144 & 3.0385 & 3.6817 & 5.0409 \\
Skewness & -0.3450 & -2.4163 & -1.6085 & -2.3739 & -0.7432 & -1.2091 & -0.8858 \\
Kurtosis & 5.3208 & 31.6728 & 20.9234 & 27.5911 & 9.0571 & 17.6096 & 14.7226 \\
J-B statistic & 158.02 & $22,928.00$ & 8989.50 & $17,010.00$ & 1052.80 & 5943.20 & 3808.10 \\
p-value & 0.00 & 0.00 & 0.00 & 0.00 & 0.00 & 0.00 & 0.00 \\
\hline \multicolumn{7}{c}{ Note: "S.D." represents standard deviation. }
\end{tabular}

The following points were observed: (1) The average growth rate of Chinese, Indian and Brazilian stock markets' index are the highest, which is consistent with the GDP growth rate of the two countries in the past 10 years, while the average of Russia is negative indicating that its stock market has performed poorly in the past decade. (2) The Standard Deviation shows that the fluctuation of emerging markets is stronger than that of developed markets as a whole, and the standard deviation of the logarithmic yield of Russian stock market index is much larger than others indicating that its stock market volatility is the most intense. (3) Skewness and Kurtosis are statistics that describe the symmetry and steepness of the data's distribution respectively. The skewness of all markets is less than 0 , indicating the data is in normal distribution deflecting to left, which means there are more extreme values at the left end of the data, and the kurtosis of all market statistics is greater than 3 , indicating that the distribution of the data is spiked, which fitting the "peak, left-leaning" characteristics of financial data. (4) The $p$-value of J-B test in all countries is less than $5 \%$, which indicates that the null hypothesis of normal distribution can be rejected. Therefore, it is necessary to adopt the function of non-normal distribution to describe the distribution of logarithmic return rate.

\subsection{Unit Root Test}

Stationarity is the most basic requirement in financial time series. Many tests for time series analysis are based on stationary time series. The unit root test is the most common and effective method for testing the stationarity of a time series. There are six main test methods: the Dickey-Fuller (DF) test, Augmented Dickey-Fuller test (ADF) test, Philips-Perron (PP) test, KPSS test, ERS test, and $\mathrm{Ng}$ and Perron (NP) test.

As the unit root test, we used the NP test, proposed by Ng and Perron, which is a nonparametric test method. The basis for determining the optimal lag order in the test is the modified AIC (Akaike information criterion). The NP test constructs four test statistics (MZa, MZt, MSB, and MPT) based on the GLS fallback principle to conduct the unit root test on the test variables. The test results are shown in Table 2.

In Table 2, the first and second columns list the results of the unit root test of the stock market's original index and logarithmic yield, respectively. The null hypothesis is that the sequence is not stationary (i.e., there is a unit root) and that the statistical value is greater than the critical value, indicating acceptance of the null hypothesis. The values of the four statistics of the stock market's original index are all greater than the critical value at the 5\% confidence level, indicating that there is no unit root in the original stock data. The four unit-root-test statistics of the logarithmic yield of each country's stock market indicate that the sequences have a unit root at a level of $1 \%$ significance. This shows that preprocessing the logarithmic yield from the stock data of financial markets is an effective way to eliminate nonstationary data. 
Table 2. Unit root test.

\begin{tabular}{ccccccccc}
\hline & \multicolumn{2}{c}{ MZa } & \multicolumn{2}{c}{ MZt } & \multicolumn{2}{c}{ MSB } & \multicolumn{2}{c}{ MPT } \\
\hline & original & return & original & return & original & return & original & return \\
CHN & -2.20 & $-128.566^{* * *}$ & -0.972 & $-8.017^{* * *}$ & 0.441 & $0.062^{* * *}$ & 10.517 & $0.191^{* * *}$ \\
USA & -2.95 & $-129.649^{* * *}$ & -1.048 & $-8.051^{* * *}$ & 0.355 & $0.062^{* * *}$ & 7.966 & $0.189^{* * *}$ \\
GBR & -1.415 & $-130.996^{* * *}$ & -0.655 & $-8.073^{* * *}$ & 0.463 & $0.062^{* * *}$ & 13.241 & $0.220^{* * *}$ \\
JPN & -4.083 & $-129.936^{* * *}$ & -1.176 & $-8.060^{* * *}$ & 0.288 & $0.062^{* * *}$ & 6.315 & $0.189^{* * *}$ \\
IND & 0.723 & $-21.214^{* * *}$ & 0.358 & $-3.219^{* * *}$ & 0.495 & $0.152^{* * *}$ & 21.431 & $2.527^{* * *}$ \\
BRA & -0.610 & $-130.763^{* * *}$ & -0.305 & $-8.08^{* * *}$ & 0.500 & $0.062^{* * *}$ & 17.107 & $0.188^{* * *}$ \\
RUS & -2.476 & $-22.6968^{* * *}$ & -0.963 & $-3.321^{* * *}$ & 0.389 & $0.146^{* * *}$ & 9.161 & $1.246^{* * *}$ \\
\hline
\end{tabular}

Note: ${ }^{* * *}, * *$ and ${ }^{*}$ indicate the rejection of the null hypothesis at the $1 \%, 5 \%$, and $10 \%$ significance levels, respectively.

\subsection{Causality of Financial Risk Contagion in Stock Markets}

Before performing the nonlinear Granger causality test on variables, we must first check whether there is a nonlinear relationship between variables. Therefore, this paper first uses the Vector Autoregression (VAR) model to filter out the linear component between the logarithmic returns of stock markets in various countries. The nonlinear correlation between the residuals is then checked based on the Brock-Dcehert-Scheinkma (BDS) test method [56].

The null hypothesis of the BDS test is that the sequences to be tested are subject to independent and identical distribution. If the time series is independently and identically distributed, its associated integral satisfies $C_{m}(\varepsilon)=C_{1}(\varepsilon)^{m}$ and the BDS statistic is as follows:

$$
U_{m, n}(\varepsilon)=\sqrt{n}\left[C_{m, n}(\varepsilon)-C_{1, n}(\varepsilon)^{m}\right] / \sigma_{m, n}(\varepsilon),
$$

where $n$ is the number of samples, $m$ is the embedded dimension, $\varepsilon$ is the distance between two points, and the standard deviation of $C_{m, n}(\varepsilon)-C_{1, n}(\varepsilon)^{m}$ is $\sigma_{m, n}(\varepsilon)$. The test results are shown in Table 3.

Table 3. Brock-Dcehert-Scheinkma Nonlinear test.

\begin{tabular}{cccccc}
\hline Causal Direction & BDS & $\boldsymbol{p}$-Value & Causal Direction & BDS & $\boldsymbol{p}$-Value \\
\hline $\mathrm{CHN} \rightarrow \mathrm{USA}$ & 0.0184 & 0.0000 & $\mathrm{USA} \rightarrow \mathrm{CHN}$ & 0.0352 & 0.0000 \\
$\mathrm{CHN} \rightarrow \mathrm{GBR}$ & 0.0168 & 0.0001 & $\mathrm{GBR} \rightarrow \mathrm{CHN}$ & 0.0165 & 0.0000 \\
$\mathrm{CHN} \rightarrow \mathrm{JPN}$ & 0.0161 & 0.0003 & $\mathrm{JPN} \rightarrow \mathrm{CHN}$ & 0.0153 & 0.0000 \\
$\mathrm{CHN} \rightarrow \mathrm{IND}$ & 0.0157 & 0.0053 & $\mathrm{IND} \rightarrow \mathrm{CHN}$ & 0.0175 & 0.0000 \\
$\mathrm{CHN} \rightarrow \mathrm{BRA}$ & 0.0133 & 0.0006 & $\mathrm{BRA} \rightarrow \mathrm{CHN}$ & 0.0161 & 0.0013 \\
$\mathrm{CHN} \rightarrow \mathrm{RUS}$ & 0.0118 & 0.0024 & $\mathrm{RUS} \rightarrow \mathrm{CHN}$ & 0.0323 & 0.0000
\end{tabular}

Note: The $p$-value from Brock-Dcehert-Scheinkma (BDS) test less than 0.05 shows a rejection of the null hypothesis that time series are independent and identically distributed (i.i.d.).

It can be seen from Table 3 that most of the BDS method tests reject the null hypothesis that "there is a linear relationship between residual sequences". Therefore, there is no significant linear relationship between the Chinese stock market and the developed stock markets and the emerging stock markets.

\subsubsection{Nonlinear Granger Causality Test of the Entire Time Period}

First, we conducted the nonlinear Granger causality test for the Chinese stock market with the developed countries' stock markets and the emerging countries' stock markets over the entire time period, as shown in Table 4.

From the perspective of developed markets, the Chinese stock market has obvious nonlinear contagion effects on the stock markets of the United States and the United Kingdom, but the nonlinear infection relationship between China and the Japanese stock market is not significant. Conversely, the US and UK stock markets have significant nonlinear contagion effects on the Chinese stock market, but the Japanese stock market has no significant nonlinear contagion effect on the Chinese stock market. 
From the perspective of emerging markets, the Chinese stock market has obvious nonlinear contagion effects on the stock markets of India and Brazil, but there is no significant nonlinear contagion effect on the Russian stock market. Conversely, emerging stock markets, whether India, Brazil, or Russia, have significant nonlinear effects on the Chinese stock market.

Table 4. Nonlinear causal checklist for the entire time period.

\begin{tabular}{ccccccc}
\hline Category & Causal Direction & Tn & $p$ & Causal Direction & Tn & $p$ \\
\hline \multirow{2}{*}{ Developed } & $\mathrm{CHN} \rightarrow$ USA & $2.3838^{* * *}$ & 0.0086 & $\mathrm{USA} \rightarrow \mathrm{CHN}$ & $2.6192^{* * *}$ & 0.0044 \\
Markets & $\mathrm{CHN} \rightarrow \mathrm{GBR}$ & $3.4350^{* * *}$ & 0.0003 & $\mathrm{GBR} \rightarrow \mathrm{CHN}$ & $3.0656^{* * *}$ & 0.0011 \\
& $\mathrm{CHN} \rightarrow \mathrm{JPN}$ & $1.8011^{*}$ & 0.0926 & $\mathrm{JPN} \rightarrow \mathrm{CHN}$ & 0.6929 & 0.2442 \\
Emerging & $\mathrm{CHN} \rightarrow \mathrm{IND}$ & $2.8836^{* * *}$ & 0.0020 & $\mathrm{IND} \rightarrow \mathrm{CHN}$ & $2.6784^{* * *}$ & 0.0037 \\
Markets & $\mathrm{CHN} \rightarrow \mathrm{BRA}$ & $3.2836^{* * *}$ & 0.0005 & $\mathrm{BRA} \rightarrow \mathrm{CHN}$ & $2.5793^{* * *}$ & 0.0050 \\
& $\mathrm{CHN} \rightarrow$ RUS & $2.1904^{* *}$ & 0.0142 & $\mathrm{RUS} \rightarrow \mathrm{CHN}$ & $2.8199^{* * *}$ & 0.0024 \\
\hline
\end{tabular}

Note: ${ }^{* *}, * *$, and $*$ indicate rejection of the null hypothesis at the $1 \%, 5 \%$, and $10 \%$ significance levels, respectively.

\subsubsection{Nonlinear Granger Causality Test Analysis of Divided Stages}

Considering that there may be some significant risk events that have a decisive effect on the stock market over a long period of time, we adopted a method of segmenting the time period of the sample to analyze the impact of specific risk events on the causality of risk contagion.

We specified two events as landmark risk events. One was the US subprime mortgage crisis in 2008, which brought huge risks to the global economy and the stock market. The second was the stock market crash in China in 2015. We tried to explore one compared with the other and observe the risk spillover effect of the national stock market. Thus, the study time period was segmented, and the divisional nonlinear causality test was divided, as shown in Table 5. The results of nonlinear causality test are shown in Tables 6 and 7.

Table 5. Division of stages of nonlinear causality test.

\begin{tabular}{ccc}
\hline Stage & Stage Description & Date Interval \\
\hline Period 1 & Before the subprime mortgage crisis & 1 January 2006-1 July 2007 \\
Period 2 & During the subprime mortgage crisis & 1 July 2007-1 January 2009 \\
Period 3 & Before Chinese stock market crash & 1 November 2014-1 June 2015 \\
Period 4 & During Chinese stock market crash & 1 June 2015-1 January 2016 \\
\hline
\end{tabular}

Table 6. Phased nonlinear causality test for the Chinese stock market and developed markets.

\begin{tabular}{|c|c|c|c|c|c|c|}
\hline Stage & Causal Direction & Tn & $p$ & Causal Direction & Tn & $p$ \\
\hline \multirow{3}{*}{ Period 1} & $\mathrm{CHN} \rightarrow \mathrm{USA}$ & -0.4152 & 0.6610 & $\mathrm{USA} \rightarrow \mathrm{CHN}$ & 0.7857 & 0.2160 \\
\hline & $\mathrm{CHN} \rightarrow \mathrm{GBR}$ & 0.7530 & 0.2257 & $\mathrm{GBR} \rightarrow \mathrm{CHN}$ & $2.1481^{* *}$ & 0.0159 \\
\hline & $\mathrm{CHN} \rightarrow \mathrm{JPN}$ & 0.9817 & 0.1631 & $\mathrm{JPN} \rightarrow \mathrm{CHN}$ & 0.1561 & 0.4380 \\
\hline \multirow{3}{*}{ Period 2} & $\mathrm{CHN} \rightarrow \mathrm{USA}$ & 1.1293 & 0.1294 & $\mathrm{USA} \rightarrow \mathrm{CHN}$ & $2.2537 * *$ & 0.0121 \\
\hline & $\mathrm{CHN} \rightarrow \mathrm{GBR}$ & 0.2821 & 0.3889 & $\mathrm{GBR} \rightarrow \mathrm{CHN}$ & $1.4625^{* *}$ & 0.0114 \\
\hline & $\mathrm{CHN} \rightarrow \mathrm{JPN}$ & 0.3254 & 0.4528 & $\mathrm{JPN} \rightarrow \mathrm{CHN}$ & $1.7779 * *$ & 0.0377 \\
\hline \multirow{3}{*}{ Period 3} & $\mathrm{CHN} \rightarrow \mathrm{USA}$ & 0.7473 & 0.2274 & $\mathrm{USA} \rightarrow \mathrm{CHN}$ & 0.4660 & 0.3206 \\
\hline & $\mathrm{CHN} \rightarrow \mathrm{GBR}$ & 0.2119 & 0.4161 & $\mathrm{GBR} \rightarrow \mathrm{CHN}$ & 0.4262 & 0.3350 \\
\hline & $\mathrm{CHN} \rightarrow \mathrm{JPN}$ & 0.4598 & 0.3228 & $\mathrm{JPN} \rightarrow \mathrm{CHN}$ & 0.1232 & 0.4510 \\
\hline \multirow{3}{*}{ Period 4} & $\mathrm{CHN} \rightarrow \mathrm{USA}$ & 0.6468 & 0.2589 & $\mathrm{USA} \rightarrow \mathrm{CHN}$ & 0.7908 & 0.2145 \\
\hline & $\mathrm{CHN} \rightarrow \mathrm{GBR}$ & 1.1102 & 0.1334 & $\mathrm{GBR} \rightarrow \mathrm{CHN}$ & -0.1646 & 0.5654 \\
\hline & $\mathrm{CHN} \rightarrow \mathrm{JPN}$ & $1.4406^{*}$ & 0.0749 & $\mathrm{JPN} \rightarrow \mathrm{CHN}$ & 0.5440 & 0.2932 \\
\hline
\end{tabular}

Note: ${ }^{* * *}, * *$, and ${ }^{*}$ indicate rejection of the null hypothesis at the $1 \%, 5 \%$, and $10 \%$ significance levels, respectively. 
Table 7. Phased nonlinear causality test for the Chinese stock market and emerging markets.

\begin{tabular}{|c|c|c|c|c|c|c|}
\hline Stage & Causal Direction & Tn & $p$ & Causal Direction & Tn & $p$ \\
\hline \multirow{3}{*}{ Period 1} & $\mathrm{CHN} \rightarrow \mathrm{IND}$ & -0.4152 & 0.6610 & $\mathrm{IND} \rightarrow \mathrm{CHN}$ & $1.2873 *$ & 0.0990 \\
\hline & $\mathrm{CHN} \rightarrow \mathrm{BRA}$ & 0.7530 & 0.2257 & $\mathrm{BRA} \rightarrow \mathrm{CHN}$ & $2.1481^{* *}$ & 0.0159 \\
\hline & $\mathrm{CHN} \rightarrow \mathrm{RUS}$ & 0.9817 & 0.1631 & $\mathrm{RUS} \rightarrow \mathrm{CHN}$ & 0.1561 & 0.4380 \\
\hline \multirow{4}{*}{ Period 2} & $\mathrm{CHN} \rightarrow \mathrm{IND}$ & $1.8247^{* *}$ & 0.0340 & $\mathrm{IND} \rightarrow \mathrm{CHN}$ & $2.2891 * *$ & 0.0110 \\
\hline & $\mathrm{CHN} \rightarrow \mathrm{BRA}$ & 0.8558 & 0.1960 & $\mathrm{BRA} \rightarrow \mathrm{CHN}$ & $2.2776^{* *}$ & 0.0114 \\
\hline & $\mathrm{CHN} \rightarrow \mathrm{RUS}$ & 1.2755 & 0.1011 & $\mathrm{RUS} \rightarrow \mathrm{CHN}$ & 1.9580 ** & 0.0251 \\
\hline & $\mathrm{CHN} \rightarrow \mathrm{IND}$ & 0.7473 & 0.2274 & $\mathrm{IND} \rightarrow \mathrm{CHN}$ & 0.4660 & 0.3206 \\
\hline \multirow[t]{2}{*}{ Period 3} & $\mathrm{CHN} \rightarrow \mathrm{BRA}$ & 0.2119 & 0.4161 & $\mathrm{BRA} \rightarrow \mathrm{CHN}$ & 0.4262 & 0.3350 \\
\hline & $\mathrm{CHN} \rightarrow \mathrm{RUS}$ & 0.4598 & 0.3228 & $\mathrm{RUS} \rightarrow \mathrm{CHN}$ & 0.1232 & 0.4510 \\
\hline \multirow{3}{*}{ Period 4} & $\mathrm{CHN} \rightarrow \mathrm{IND}$ & 0.6468 & 0.2589 & $\mathrm{IND} \rightarrow \mathrm{CHN}$ & 0.7908 & 0.2145 \\
\hline & $\mathrm{CHN} \rightarrow \mathrm{BRA}$ & 1.1102 & 0.1334 & $\mathrm{BRA} \rightarrow \mathrm{CHN}$ & -0.1646 & 0.5654 \\
\hline & $\mathrm{CHN} \rightarrow \mathrm{RUS}$ & $1.4406^{*}$ & 0.0749 & $\mathrm{RUS} \rightarrow \mathrm{CHN}$ & 0.5440 & 0.2932 \\
\hline
\end{tabular}

Note: ${ }^{* * *},{ }^{* *}$, and ${ }^{*}$ indicate rejection of the null hypothesis at the $1 \%, 5 \%$, and $10 \%$ significance levels, respectively.

The results of phased nonlinear causal relationships between the Chinese stock market and the developed stock markets can be summarized as follows. (1) Before the subprime mortgage crisis the Chinese stock market had no contagious effect on the developed stock market, but the United States and the UK stock markets had some contagion effects on the Chinese stock market. (2) During the subprime mortgage crisis China had no obvious contagion effect on the developed countries and only a slight contagion effect on the US stock market, but the US, UK, and Japanese stock markets all had an obvious contagion effect on the Chinese stock market, indicating that the Chinese stock market became the acceptor of developed countries' stock market risks. (3) Before the Chinese stock market crash there was no obvious contagion effect between the Chinese stock market and developed countries' stock markets. (4) During the Chinese stock market crash the Chinese stock market had a more significant contagion effect on the Japanese stock market. However, the Chinese stock market had no obvious contagion effect on the US and UK stock markets. This shows that when China is the source of the risk, the Chinese stock market has a greater contagion effect on Japan than it has on the United States and the United Kingdom.

The results of phased nonlinear causal relationships between the Chinese stock market and the emerging stock markets can be summarized as follows. (1) Before the subprime mortgage crisis, the Chinese stock market had no contagious effect on emerging stock markets; instead, India and Brazil had some contagious effect on China. (2) During the subprime mortgage crisis the Chinese stock market only had a slight contagious effect on the Indian stock market, but the stock markets of India, Brazil, and Russia generally had a significant contagious effect on the Chinese stock market, indicating that during the subprime crisis China became a risk acceptor of emerging markets. (3) Before the Chinese stock market crash, there is no obvious contagion effect between the Chinese stock market and the developed countries' stock markets. (4) During the Chinese stock market crash the contagion effect of the Chinese stock market on the Russian stock market was more significant, while the Chinese stock market had no obvious contagion effect on India and Brazil, indicating that Russia was more obviously affected by the sharp fall in the Chinese stock market.

\subsection{Measurement of Financial Risk Contagion in Stock Markets}

Academically, financial risk contagion can be quantified by the probability that the stock market index of the country from which the risk originates will change dramatically and lead to the same extreme change in the financial market of the infected country [57-60].

This concept is consistent with determining the lower tail coefficient of dependence between two countries' stock market index logarithmic returns. Therefore, we calculated the time-varying lower tail dependence coefficient based on the above model, as shown in Figures 3 and 4. 


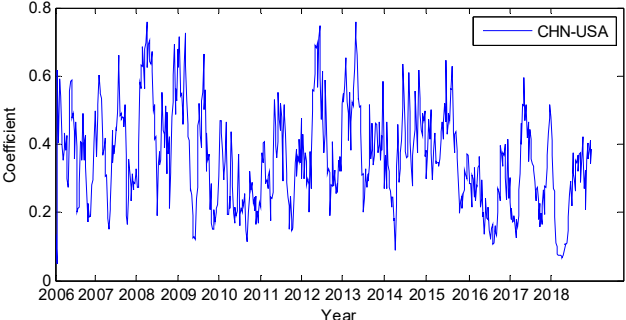

(a)

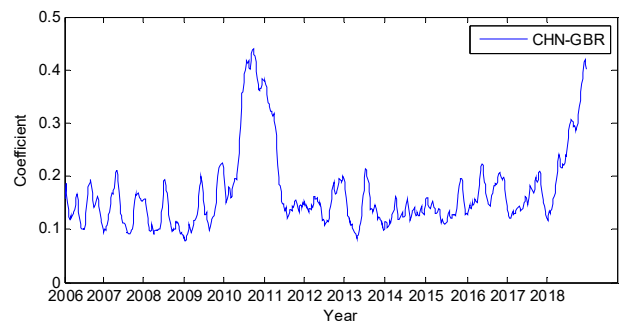

(b)

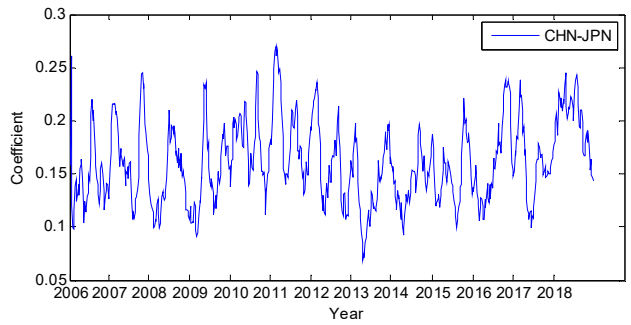

(c)

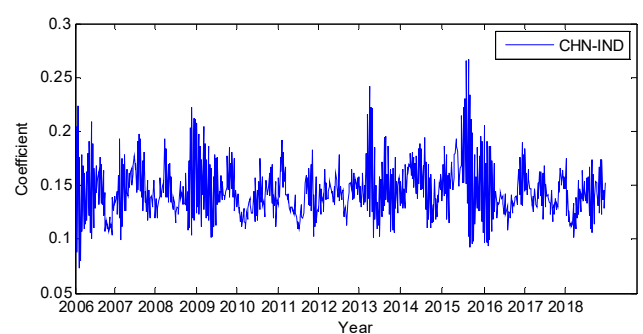

(d)

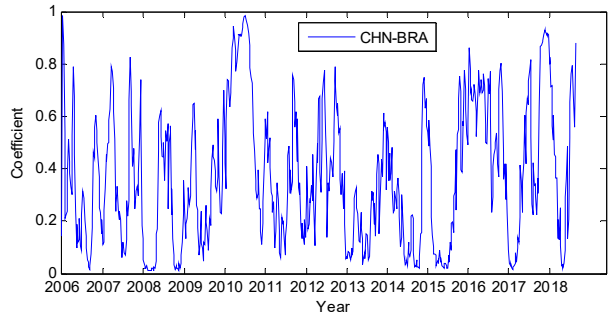

(e)

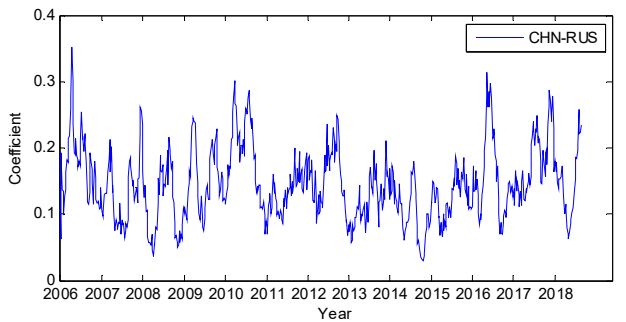

(f)

Figure 3. Dynamic lower tail dependence coefficients of 6 pairs: (a) CHN and USA; (b) CHN and GBR; (c) CHN and JPN; (d) CHN and IND; (e) CHN and BRA; (f) CHN and RUS.

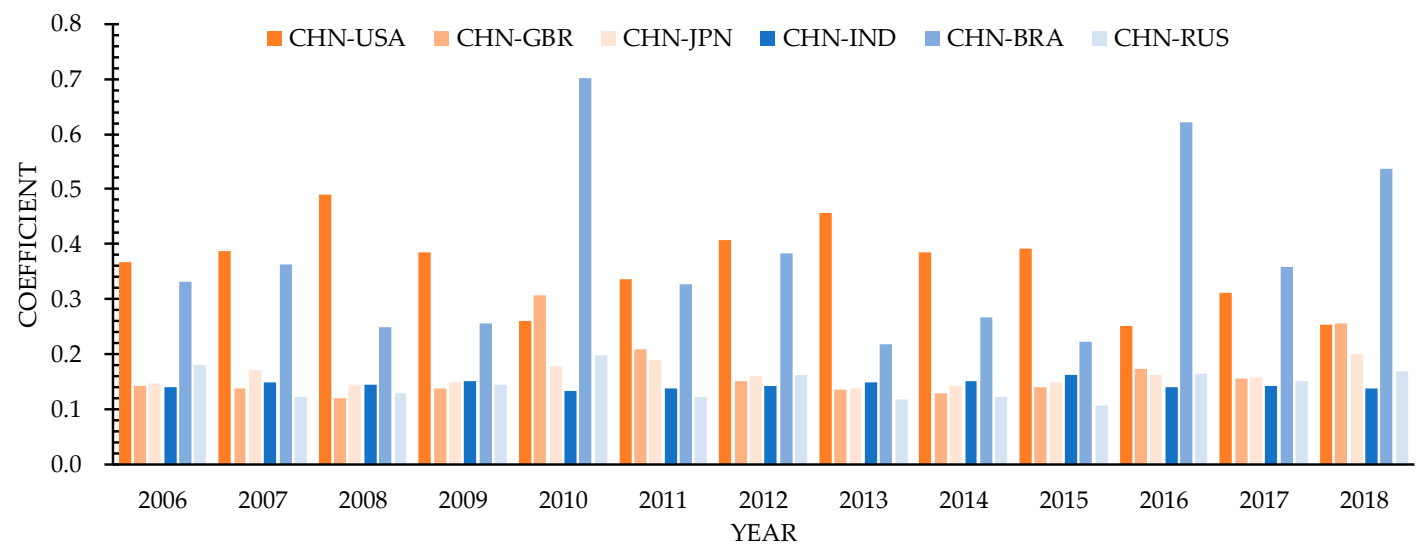

Figure 4. Annual average of dynamic lower tail dependence coefficients of six pairs.

The results of measurement of financial risk contagion in stock markets can be summarized as follows. From examining risk contagion effects on developed stock markets, the lower tail dependence correlation coefficients between the Chinese stock market and developed stock markets increased significantly in the first half of 2008, primarily due to the impact of risk contagion caused by the outbreak of the subprime mortgage crisis in the United States. In June 2015, the dependence coefficient between developed stock markets and Chinese stock markets also rose to varying degrees. The main reason is the impact of risk contagion caused by the Chinese stock market disaster. The stock markets of emerging countries follow the same rules as those of developed countries. There was a certain risk contagion effect between the Chinese stock market and the developed and emerging markets, and 
the degree of contagion in different markets varied in different periods. Structural change refers to the change of the deterministic trend of economic time series when it is subjected to strong external shocks. Therefore, the study of structural change during the sample period is conducive to revealing the interdependence and time-varying nature of stock markets in more detail. This paper adopts the method proposed by Bai and Perron $[61,62]$ to detect the breakpoint of dynamic correlation coefficient, which is based on the idea of dynamic programming and sequential test method, as shown in Table 8 .

Table 8. Breakpoint test based on global information citations.

\begin{tabular}{ccccc}
\hline Pair & Breakpoint 1 & Breakpoint 2 & Breakpoint 3 & Breakpoint 4 \\
\hline CHN-USA & $2009 / 4 / 27$ & $2012 / 4 / 2$ & $2015 / 10 / 5$ & \\
CHN-GBR & $2009 / 10 / 26$ & $2011 / 9 / 26$ & $2016 / 4 / 25$ & \\
CHN-JPN & $2009 / 10 / 26$ & $2012 / 4 / 9$ & $2016 / 7 / 25$ & \\
CHN-IND & $2014 / 2 / 17$ & $2016 / 1 / 11$ & & \\
CHN-BRA & $2010 / 2 / 22$ & $2013 / 2 / 18$ & $2015 / 12 / 28$ & \\
CHN-RUS & $2009 / 3 / 30$ & $2011 / 2 / 28$ & $2013 / 3 / 4$ & $2016 / 7 / 18$ \\
\hline
\end{tabular}

Notes: The date is given by Year/Month/Day. Breakpoint selection is based on the Schwarz criterion.

The interdependence between the stock markets increased in general from 2006 to 2018, increased significantly in 2008, and declined from 2013. There are two to four structural breakpoints in the dependence between stock markets, which mainly occur in in 2008-2009, 2011-2013, and 2015-2016. Most of these years have been accompanied by financial crisis or changes in economic prospects of one or more countries, which are related to the economic and financial fundamentals of various countries.

Similar to the results of the previous studies, we tend to think that the dramatic changes in risk contagion under specific risk events are mainly due to investor sentiment. In order to explore the impact of capital globalization, we use securities investment in Balance of Payments Statement of China to reflect the degree of international capital flows between China and foreign countries, in which assets represent China's investment in foreign securities and liabilities represent foreign investment in China's securities, as shown in Figure 5.

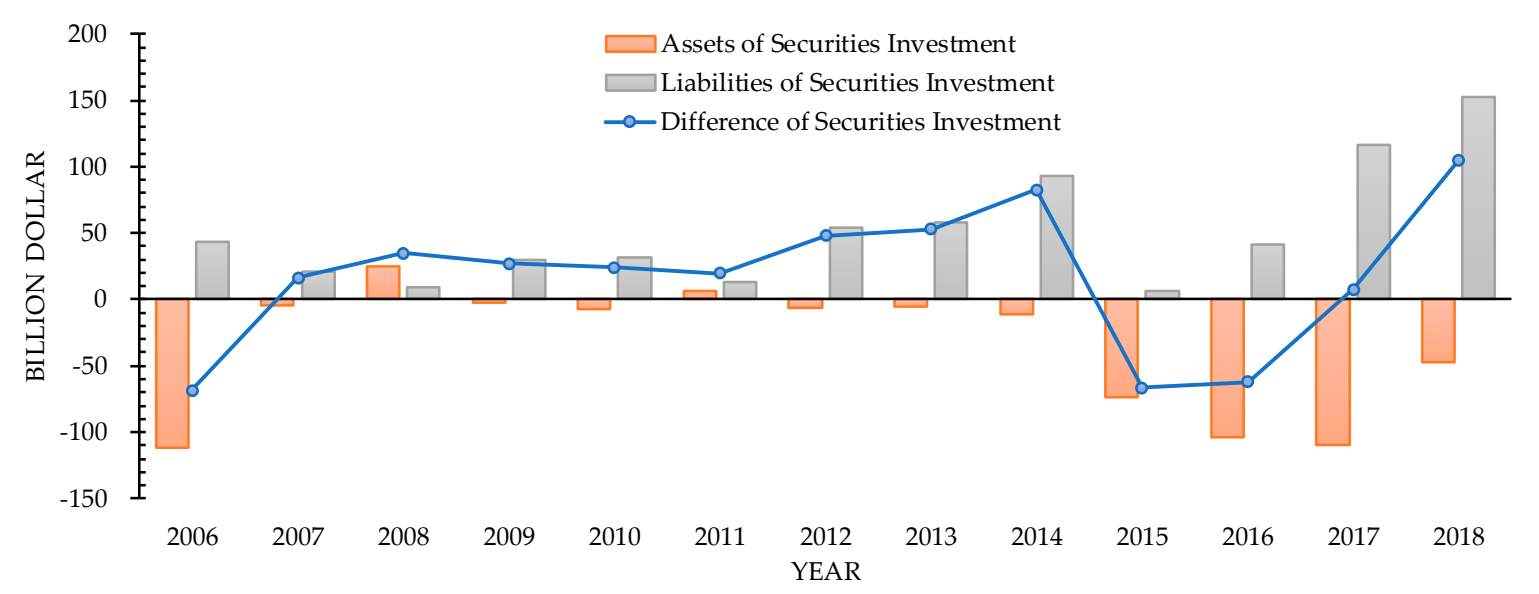

Figure 5. The historical trend of securities investment in Balance of Payments Statement of China.

According to our findings, the overall trend of securities investment balance has been increasing year by year in the past decade, but there are still some fluctuations in the middle. During 2015 and 2016, the fluctuation of RMB exchange rate increased the risk premium, resulting in serious capital outflow. At the same time, the tail correlation between China's stock markets and other countries has also declined significantly. During 2017 and 2018, with the opening up of China's financial market, such as the incorporation of China's A-share into MSCI global benchmark index, Shanghai-London stock connect and so on, the enthusiasm of investors in other countries for China's securities investment 
has increased dramatically, resulting in a significant increase in the two-way capital flow during this period, followed by a significant increase in the tail correlation between China's stock markets and other countries.

\section{Conclusions}

From the empirical results, with the gradual opening up of the financial sector, the relatively closed Chinese stock market has gradually strengthened its correlation with international capital markets under the influence of international capital inflows. The Chinese stock market is also increasingly susceptible to other international markets. The risk of market infection has a tendency to develop in a manner similar to people infecting other people to some extent. The specific research has the following conclusions.

For the causality of financial risk contagion in stock markets overall, in the developed markets, the Chinese stock market is more closely linked to the US and UK stock markets, while in emerging markets, India and Brazil are more closely linked to the Chinese stock market. During the outbreak of the subprime mortgage crisis both the developed markets and the emerging markets had obvious contagion effects on the Chinese stock market, while the Chinese stock market rarely affected other stock markets. It can be seen that, compared with before the outbreak of the subprime mortgage crisis, the Chinese stock market acted as a risk receiver in the global risk communication network. However, during the outbreak of the Chinese stock market crash the Chinese stock market took on the infector role, and had obvious risk contagion effects on Japan and Russia, countries which had little effect on the original infection. This indicates that the output of Chinese stock market risk mainly affected Japan and Russia among the countries studied in this paper.

From the measurement of financial risk contagion in stock markets after the occurrence of specific risk events, the dynamic tail coefficient of the Chinese stock market and developed and emerging markets increased significantly, and the risk contagion effect of developed markets and the Chinese stock market became more pronounced. That is to say, whether during the outbreak of the US subprime mortgage crisis or during the Chinese stock market crash, there was a certain risk contagion effect between the Chinese stock market and developed and emerging markets, but the degree of infection in different markets varied for different times. When specific risk events occur in the peripheral market, changes in investor sentiment will impact the stock market, which is the common cause of risk contagion. In addition, considering the stock market as a huge and complex economic ecosystem, international capital flows will also have an important impact on the balance of the system.

The above conclusions show that the stock markets of different countries have symbiosis under the background of economic globalization, and risk has a mutual accumulation relationship. The occurrence of specific risk events and the increase of capital flows between countries have a certain effect on the lower tail dependence correlation. Regulators and relevant market entities should strengthen the education of investors and create a good environment for value-investing. Then the impulsive irrational behavior caused by investor sentiment will be reduced when the risk event occurs, and the negative impact of risk contagion on the sustainability of financial markets will also be reduced. Since there is an obvious phenomenon of financial risk contagion in the stock markets, the government can use the price discovery function of futures to enrich futures varieties and hedge risks. At the same time, the government can establish a sound monitoring system, through the dynamic monitoring of risk linkage, especially when the dynamic correlation increases significantly, the protection mechanism can be used to avoid the spread of financial risks, so as to promote the healthy and sustainable development of social economy and financial market.

Compared with previous studies, we have drawn more specific and comprehensive conclusions from the causality and measurement of risk contagion. In particular, we pay attention to the difference between the direction of risk contagion under the subprime mortgage crisis and China's stock market disaster in 2015. In addition, this paper not only explores the increase of risk contagion under 
specific risk events, but also finds the trend of risk contagion in the past decade with the opening of capital account.

Due to the length of the paper, the representative stock markets of developed and emerging countries are selected separately, which is a limitation of the research. As for the direction of future research, we can consider including multiple countries into the research scope, and adopt some methods suitable for more countries, such as Minimum Spanning Tree (MST), Planar Maximum Filter Graph (PMFG), and Susceptible Infected Recovered (SIR). In addition, we can develop new statistical methods to accurately judge the development stages of financial crisis contagion, such as some hypothesis tests to judge the crisis, so as to better quantify the financial risk contagion.

Author Contributions: In this research activity, all authors were involved in the data collection and preprocessing phase, empirical research, results analysis and discussion, and manuscript preparation. All authors have approved the submitted manuscript.

Funding: This research was funded by Shanghai University of Finance and Economics (in 2016) grant number (CXJJ-2016-427).

Acknowledgments: We are grateful to three anonymous referees for helpful comments and suggestions. We would like to express our gratitude to them for their help and guidance.

Conflicts of Interest: The authors declare no conflict of interest.

\section{References}

1. Das, S.R.; Uppal, R. Systemic risk and international portfolio choice. J. Financ. 2004, 59, 2809-2834. [CrossRef]

2. Dimitriou, D.; Kenourgios, D.; Simos, T. Global financial crisis and emerging stock market contagion: A multivariate FIAPARCH-DCC approach. Int. Rev. Financ. Anal. 2013, 30, 46-56. [CrossRef]

3. Bekaert, G.; Ehrmann, M.; Fratzscher, M.; Mehl, A. The Global Crisis and Equity Market Contagion. J. Financ. 2014, 69, 2597-2649. [CrossRef]

4. Zhang, P.; Qin, G.J.; Wang, Y.H. Optimal Maintenance Decision Method for Urban Gas Pipelines Based on as Low as Reasonably Practicable Principle. Sustainability 2019, 11, 153. [CrossRef]

5. Cook, D.O.; Spellman, L.J. Firm and Guarantor Risk, Risk Contagion, and the Interfirm Spread among Insured Deposits. J. Financ. Quant. Anal. 1996, 31, 265-281. [CrossRef]

6. Beirne, J.; Fratzscher, M. The pricing of sovereign risk and contagion during the European sovereign debt crisis. J. Int. Money Financ. 2013, 34, 60-82. [CrossRef]

7. He, B.J.; Zhao, D.X.; Zhu, J.; Darko, A.; Gou, Z.H. Promoting and implementing urban sustainability in China: An integration of sustainable initiatives at different urban scales. Habitat Int. 2018, 82, 83-93. [CrossRef]

8. Pais, A.; Stork, P.A. Contagion risk in the Australian banking and property sectors. J. Bank. Financ. 2011, 35, 681-697. [CrossRef]

9. Wang, K.M. Did Vietnam stock market avoid the "contagion risk" from China and the U.S.? The contagion effect test with dynamic correlation coefficients. Qual. Quant. 2013, 47, 2143-2161. [CrossRef]

10. Nolde, N.; Zhang, J. Conditional Extremes in Asymmetric Financial Markets. Soc. Sci. Electron. Publ. 2018. [CrossRef]

11. Longin, F.; Solnik, B. Is the correlation in international equity returns constant: 1960-1990. J. Int. Money Financ. 1995, 14, 3-26. [CrossRef]

12. Yilmaz, K. Return and volatility spillovers among the East Asian equity markets. J. Asian Econ. 2010, 21, 304-313. [CrossRef]

13. Granger, C.W.J. Investigating Causal Relations by Econometric Models and Cross-spectral Methods. Econometrica 1969, 37, 424-438. [CrossRef]

14. Harald, S.; Kleimeier, S. Contagion and Causality: An Empirical Investigation of Four Asian Crisis Episodes. J. Int. Financ. Mark. Inst. Money. 2003, 13, 171-186.

15. Okunev, J.; Wilson, P.; Zurbruegg, R. The Causal Relationship Between Real Estate and Stock Markets. J. Real Estate Financ. Eco. 2000, 21, 251-261. [CrossRef]

16. Brock, W.A.; Baek, E.G. Some theory of statistical inference for nonlinear science. Rev. Econ. Stud. 1991, 58, 697-716. [CrossRef] 
17. Jones, J.D.; Hiemstra, J. Testing for Linear and Nonlinear Granger Causality in the Stock Price- Volume Relation. J. Financ. 1994, 49, 1639-1664.

18. Diks, C.; Panchenko, V. A new statistic and practical guidelines for nonparametric Granger causality testing. J. Econ. Dyn. Control 2006, 30, 1647-1669. [CrossRef]

19. Bekiros, S.D.; Diks, C.G.H. The relationship between crude oil spot and futures prices: Cointegration, linear and nonlinear causality. Energy Econ. 2008, 30, 2673-2685. [CrossRef]

20. Chen, H.; Cummins, J.D.; Viswanathan, K.S.; Weiss, M.A. Systemic Risk and the Interconnectedness Between Banks and Insurers: An Econometric Analysis. J. Risk Insur. 2014, 81, 623-652. [CrossRef]

21. Gómez-Puig, M.; Sosvilla-Rivero, S. Causality and contagion in EMU sovereign debt markets. Int. Rev. Econ. Financ. 2014, 33, 12-27. [CrossRef]

22. De, V.G.; Trachanas, E.; Luo, Y. Revisiting the bi-directional causality between debt and growth: Evidence from linear and nonlinear tests. J. Int. Money Financ. 2018, 83, 55-74.

23. Pearson, K. Notes on regression and inheritance in the case of two parents. Proc. R. Soc. Lond. 1895, 58, 240-242.

24. King, M.A.; Wadhwani, S. Transmission of Volatility between Stock Markets. Rev. Financ. Stud. 1990, 3, 5-33. [CrossRef]

25. Engle, R. Dynamic Conditional Correlation: A Simple Class of Multivariate Generalized Autoregressive Conditional Heteroskedasticity Models. J. Bus. Econ. Stat. 2002, 20, 339-350. [CrossRef]

26. Chiang, T.C.; Jeon, B.N.; Li, H. Dynamic correlation analysis of financial contagion: Evidence from Asian markets. J. Int. Money Financ. 2007, 26, 1206-1228. [CrossRef]

27. Syriopoulos, T.; Makram, B.; Boubaker, A. Stock market volatility spillovers and portfolio hedging: BRICS and the financial crisis. Int. Rev. Financ. Anal. 2015, 39, 7-18. [CrossRef]

28. Sklar, A. Fonctions de répartition à n dimensions et leurs marges. Publ. De L'institut De Stat. De L'universitè De Paris 1959, 8, 229-231.

29. SatishsIyengar. Multivariate Models and Dependence Concepts. Technometrics 1998, 40, 1.

30. Nelsen, R.B. An Introduction to Copulas. Springer Series in Statistics, 2nd ed.; Springer: New York, NY, USA, 2006.

31. Jondeau, E.; Rockinger, M. The Copula-GARCH model of conditional dependencies: An international stock market application. J. Int. Money Financ. 2006, 25, 827-853. [CrossRef]

32. Wang, C.; Zhang, B.; Jiang, Y. Quantitative measurement of the contagion effect between US and Chinese stock market during the financial crisis. Phys. A Stat. Mech. Its Appl. 2014, 410, 550-560.

33. Adler, M.; Dumas, B. International Portfolio Choice and Corporation Finance: A Synthesis. J. Financ. 1983, 38, 925-984. [CrossRef]

34. Eun, C.S.; Resnick, B.G. Exchange Rate Uncertainty, Forward Contracts, and International Portfolio Selection. J. Financ. 2012, 43, 197-215. [CrossRef]

35. Forbes, K.J.; Rigobon, R. No Contagion, Only Interdependence: Measuring Stock Market Comovements. J. Financ. 2010, 57, 2223-2261. [CrossRef]

36. Darrat, A.F.; Zhong, M. Permanent and Transitory Driving Forces in the Asian-Pacific Stock Markets. Financ. Rev. 2002, 37, 35-51. [CrossRef]

37. Jian, Y. Contagion around the October 1987 stock market crash. Eur. J. Oper. Res. 2008, 184, 291-310.

38. Tsuji, C. Return transmission and asymmetric volatility spillovers between oil futures and oil equities: New DCC-MEGARCH analyses. Econ. Model. 2018, 74, 167-185. [CrossRef]

39. Cai, X.J.; Tian, S.; Hamori, S. Stock Market Integration in China: Evidence from the Asymmetric DCC Model and Copula Approach. Appl. Econ. Financ. 2016, 4, 1-10. [CrossRef]

40. Tsuji, C. New DCC analyses of return transmission, volatility spillovers, and optimal hedging among oil futures and oil equities in oil-producing countries. Appl. Energy 2018, 229, 1202-1217. [CrossRef]

41. Girardi, G.; Ergün, A.T. Systemic risk measurement: Multivariate GARCH estimation of CoVaR. J. Bank. Financ. 2013, 37, 3169-3180. [CrossRef]

42. Yang, L.; Ma, J.; Hamori, S. Dependence Structures and Systemic Risk of Government Securities Markets in Central and Eastern Europe: A CoVaR-Copula Approach. Sustainability 2018, 10, 324. [CrossRef]

43. Reboredo, J.C.; Ugolini, A. Systemic risk in European sovereign debt markets: A CoVaR-copula approach. J. Int. Money Financ. 2014, 51, 214-244. [CrossRef] 
44. Kantelhardt, J.W. Multifractal detrended fluctuation analysis of nonstationary time series. Phys. A Stat. Mech. Its Appl. 2002, 316, 87-114. [CrossRef]

45. Souza, J.D.; Queiros, S.M.D. Effective multifractal features and l-variability diagrams of high-frequency price fluctuations time series. Chaos Solitons Fractals 2009, 42, 2512-2521. [CrossRef]

46. Adam, K.; Marcet, A.; Nicolini, J.P. Stock Market Volatility and Learning. J. Financ. 2016, 71, 419-438. [CrossRef]

47. Longin, F.; Solnik, B. Extreme Correlation of International Equity Markets. J. Financ. 2001, 56, 649-676. [CrossRef]

48. Olsenrobert, A. Behavioral Finance and Its Implications for Stock-Price Volatility. Financ. Anal. J. 2006, 54, $10-18$.

49. Engle, R.F.; Ng, K.V. Measuring and Testing the Impact of News on Volatility. J. Financ. 1993, 48, 1749-1778. [CrossRef]

50. Hansen, B.E. Autoregressive Conditional Density Estimation. Int. Econ. Rev. 1994, 35, 705-730. [CrossRef]

51. Juri, A.; Mario, V.W. Copula Convergence Theorems for Tail Events. Insur. Math. Econ. 2002, 30, 405-420. [CrossRef]

52. Patton, A.J. Modelling Asymmetric Exchange Rate Dependence. Int. Econ. Rev. 2006, 47, 527-556. [CrossRef]

53. Patton, A.J. Estimation of Multivariate Models for Time Series of Possibly Different Lengths. J. Appl. Econom. 2006, 21, 147-173. [CrossRef]

54. Granger, C.W.J.; Teräsvirta, T.; Patton, A.J. Common factors in conditional distributions for bivariate time series. J. Econom. 2006, 132, 43-57. [CrossRef]

55. Ng, S.; Perron, P. LAG Length Selection and the Construction of Unit Root Tests with Good Size and Power. Econometrica 2001, 69, 1519-1554. [CrossRef]

56. Brock, W.A.; Dechert, W.; Scheinkman, J.; LeBaron, B. A test for independence based on the correlation dimension. Econom. Rev. 1996, 15, 197-235. [CrossRef]

57. Filho, O.C.D.S.; Ziegelmann, F.A.; Dueker, M.J. Modeling dependence dynamics through copulas with regime switching. Insur. Math. Econ. 2012, 50, 346-356. [CrossRef]

58. Fei, F.; Fuertes, A.M.; Kalotychou, E. Dependence in credit default swap and equity markets: Dynamic copula with Markov-switching. Int. J. Forecast. 2017, 33, 662-678. [CrossRef]

59. Zhu, H.M.; Li, R.; Li, S. Modelling dynamic dependence between crude oil prices and Asia-Pacific stock market returns. Int. Rev. Econ. Financ. 2014, 29, 208-223. [CrossRef]

60. Wen, X.; Yu, W.; Huang, D. Measuring contagion between energy market and stock market during financial crisis: A copula approach. Energy Econ. 2012, 34, 1435-1446. [CrossRef]

61. Perron, P.; Bai, J. Estimating and Testing Linear Models with Multiple Structural Changes. Econometrica 1998, $66,47-78$.

62. Bai, J.; Perron, P. Multiple Structural Change Models: A Simulation Analysis. J. Appl. Econom. 2003, 18, 1-22. [CrossRef]

(C) 2019 by the authors. Licensee MDPI, Basel, Switzerland. This article is an open access article distributed under the terms and conditions of the Creative Commons Attribution (CC BY) license (http:/ / creativecommons.org/licenses/by/4.0/). 